\title{
Research on Quality of Kindergarten's Facilities Based on Children's Perspectives
}

\author{
Chen Huan \\ Department of Education, Northeast Normal University, Changchun, Jilin, China, 130024 \\ 346591653@163.com
}

Keywords: children's perspectives, kindergarten, quality of facilities

\begin{abstract}
Paying attention to the children's opinions and listening to the children's heart are very important to the formulating the kindergarten's plan and improving education objectives. This research made use of the random sampling and purposive sampling and chose 325 -years-old kids to recognize their degree of satisfaction towards facilities which they frequently use through the interview. The research shows that: The difficulty and function are the important factors of the quality of kindergarten facilities based on the children's perspectives. The less important factors include arrangement, physical character, allocation quantity, service and clean, opportunities and allowable time. The kindergarten should create the facilities which can match the education goals and attract the children.
\end{abstract}

\section{The Raise of the Question}

The study of "kindergarten's facilities" refers only to the physical environment created for children and closely related to children's learning and life, mainly including the outdoor environment, angular environment, wall environment and living environment. Other environments, such as teacher's office, lounge, etc. are not in the scope of this study.

The facilities of kindergarten play an important role in the healthy development of children. The standards promulgated by NAEYC (National Association for the Education of Young Children) in 1998 pointed out that high quality of kindergarten physical environment can promote the relationship between teachers, the relationship between kindergartens and children and the relationship between kindergarten and family. In recent years, the research on facilities in the kindergarten mainly develops into two categories. One is based on the adult's perspective. It mainly focus on the physical environment should reach the goal of education. The viewpoint of the research focuses on teachers, experts and the views of parents. The other is based on the children's perspectives. It mainly focuses on the attitude and choice of children to the facilities. The research believes the facilities which only children are willing to use can make sense.

Domestic research is mainly still based on the adults' perspectives, lacking of the research based on children's perspectives. In this study, we explored the quality of facilities in kindergarten from the perspective of children.

\section{The Method of the Research}

\section{A: The Method of Collecting the Data}

The use of big data technology can greatly promote the government information disclosure to create the basic conditions for public participation in public management. Citizens can express the 
opinions and suggestions of the government's public administration in the government's portal websites through online comments and comments. The local government can also use social networks, mass media and other media to expand public participation channels. For example, the establishment of community public forum, so that the community residents in the forum to freely and fully express their views, the government through the forum to listen to public opinion and suggestions, so as to improve public management. Public organizations and the people participate in public management, in addition to the need to actively guide and encourage the government, but also by the public awareness of participation, participation, etc.. Therefore, under the background of big data, to construct the multi management pattern of public management, the government is trying to expand the channels of citizen participation, and through the media, network, communication and other tools for public opinion to carry out positive attention, from the objective. It also helps to achieve the goal of public governance. Big data technology can help the government to obtain a large amount of data in real time, through the data mining and analysis, which can also capture the public opinion, the demand and innovative suggestions from the public. Decision makers to make scientific and rational decisions by actively concerned about public opinion. In the process of the public management, the government has actually practiced the concept of collaborative management.

We selected two top classes in two public kindergartens (A, B) and took photos for the facilities created for the children in the kindergartens. We took 299 photos and encoded the photos based on "Kindergarten Directory of Teaching Tools and Toys". We randomly selected 10 children in each class to participate in the pre-interview. And then we did the purposive sampling according to their language expression ability and willingness to participate. Finally, 32 interviews including 16 boys and 16 girls were determined. After several pre interview, combined with the characteristics of the research object to determine the following data collection process. We had the interview one by one to ask children: "What face will you give? (laughing face, no facial expression or crying face) and "why?". The interview generally lasted for 25 minutes. We kept the interview tapes without informing the children and recorded the interview content.

\section{B: The Method of Analyzing the Data}

We analyzed the amount of satisfaction of the children and divide it into three grades. The satisfaction was recorded as 3; the just so-so was recorded as 2; the dissatisfaction was recorded as 1. Firstly, we transcribed, encoded, sorted and supplemented the original data; secondly we extracted the keywords based on the accurate grasp of the meaning of children's language; finally, we classified, induced and abstracted seven factors children often referred to.

\section{Research Results and Analysis}

\section{A: Current Situation of outside Environment Quality Based on Children's Perspectives}

In the explanation of the children's satisfaction, the factor of difficulty occurs more often than any other factors and it accounts for $50 \%$ of the total. Function ranks second, accounting for $18 \%$. Other factors account for $26 \%$.

Difficulty. In explaining the difficulty of children's satisfaction, the $59 \%$ difficulty is appropriate, and the remaining $41 \%$ are too simple or difficult. Children think suitable difficulty showed the following characteristics: emphasizing the sense of competence, frequent use of "win", "cut" and other words; II emphasizes speed, frequent use of "fast", "no shadow" and other words. Some children even if one considers the suitable difficulty still puts forward suggestions for improvement, such as "if the swing has sitting behind the stool soft fence, you head can lean on it and you will be more comfortable". 
Function. For non-sports facilities and outdoor venues, children believed that the situation was effective in $83 \%$. When its basic function played an important role in children's daily life, children paid close attention to its basic functions. Conversely, they focused on its game features, such as "we can play leaves rain in almond groves in autumn", "sometimes we went there to slide.". Children of corridor, pavilion and other venues satisfaction lowest because of its neither game function and not in daily life play an important role.

Others. Children are more concerned about the size and appearance of two physical characteristics, especially for just to allow the body of the hole has a strong interest. Children are only mentioned the opportunity and time only restricted, urging parents to leave the garden, kindergarten limit outdoor activities time, teachers designated place for outdoor activities is the main limiting factor, such as "my daddy said after work son childhood friends can't play", "this child is not allowed to enter, security uncle to sow the land...". For the maintenance and cleaning of children also speak only of negative circumstances, and is often easy to overlook the details. For example, "I'm afraid...... The teachers cannot see the ants until they climb up to see".

\section{B: Current Situation of Angular Environment Quality Based on Children's Perspectives}

Angular environment is the most abundant environment. Allocation quantity accounts for $52 \%$ of the total.

Function. Children are mainly concerned with the effectiveness and sufficiency of the basic function of the material. The effectiveness of the function is basically affirmed. The reasons are not sufficient: the lack of key functions, such as: "if this phone really can speak, it is good, not really dial out but can really talk......" The shape of the restrictions, for example, this can only take a house, what cannot take". Also, children think should be added some role-playing material to make up for the loss of function, such as "best small friends have a hook infusion, so the doctor is no has been the", "hospital should also have sugar, children kick down the needle will cry, and the medicine is bitter. You should put in some sugar and he will not cry".

Difficulty. Difficulty is the main factor that affects children's satisfaction with language materials. Analysis revealed that children think language materials generally because of literacy amount is too large and too difficult, especially bilingual and English books; spatial relations, sorting, comparison class scientific enlightenment material degree of difficulty is appropriate; and operation and to use mathematical knowledge to solve the problem of material is too difficult, the reasons are: content is too difficult, such as "I don't like addition and subtraction, I like math interesting...... But add and subtract are more difficult than mathematics. Mathematics is the number "; secondly, the using way is not clear, such as" I don't know how to play the sticks. I don't like thenm. It's a little hard to know how to play".

Others. For opportunity and time children still mainly mentioned subject to constraints, including limit their use art and music class materials, limit children's choice for the role and the role of material usage, such as "I when a doctor", "attendant is responsible to bring vegetables, teacher say don't let them cook out and restrictions on the use of time. The maintenance and cleaning of the material properties of the children are mainly concerned with the maintenance, especially the construction of materials. I don't like it, because my wings are broken ". Physical characteristics of the shape and color and other appearance based, not satisfied with the reasons for the main material size is too small, such as "the pot is too small, what things cannot be installed. Although there is a bowl, but you see these two are too small". Equipped with the amount of children are not satisfied with the situation, the reason is too much or too little, the area is not suitable and accessories. Excessive number will increase the difficulty of material, such as "the digital knowledge is the 
understanding, I can't play too much turn"; it can also cause idle, such as "there are not so many guests and we do not know how to use so many spoons."

\section{C: Current Situation of Wall Environment Quality Based on Children's Perspectives}

Generally speaking, the amount of satisfaction of ornamental wall environment is lowest (1.98), but the amount of satisfaction of the education-subject wall environment is highest (2.51).

Function. Children more agree with the basic function of the conventional functional wall environment, the reasons for the functional dissatisfaction include: do not understand, for example, this is the theme of the wall, affixed to it...... Don't know why, she every day are on the table get this thing and posted on the wall "; secondly, understand but consider it useless" welcome friends a bit useless, watching the teacher we welcome not ", mainly for decorative wall environment; thirdly, they do not use or are no longer use, such as" rewarding belongs to us, but now it's useless".

The difficulty accounts for the major proportion. The material literacy levels are higher than that of early childhood, such as "I don't know, we could not read"; or higher than cognitive abilities, such as "I just don't like it, I don't understand what teacher fold". Difficult to account for 29\%, although children have used many times, I can, I will, and other words, but its body language is better to talk about the rich environment, the mood is more stable.

Others. Physical characteristics mainly refer to the material to the appearance of the main material. The individual children mentioned in the wall environment of the word are too small, not easy to identify. Opportunities and time in the use of no experience in $2 / 3$, which have an important impact on children's satisfaction; the use of restricted accounts for $1 / 3$, little impact on children's satisfaction. Layout factors are negative evaluation, including: the aisle, corridors, stairs and other crowded, such as "I have not played, every home here are a lot of people"; the height is too high, such as"...... But I can't see what's on it...... There are a lot of words I can't see clearly". Maintenance and cleaning accounted for 3\%. They are all negative evaluation.

\section{D: Current Situation of Living Environment Quality Based on Children's Perspectives}

The average satisfaction of children to living environment is the highest, and the difference is the smallest. Unknown factor refers to the children only said "convenient", "very good use", "nothing is not good", even if the interviewer to ask also no added, and only in the case of children's satisfaction.

Children mainly focus on the basic functions of living facilities and the results are mainly satisfaction. The dissatisfaction reasons are "no longer use" or "not to use", such as "duty clothes, never have". Maintenance with clean is given priority to with the children's dissatisfaction, and other categories of environment as many appear in adults is easy to ignore in place, such as "I think shoe rack has been a problem, is shaking to sway to the problem." Physical characteristics accounted for $9 \%$ of the children's living environment satisfaction. The children mainly focus on the size, not the appearance. Equipped with accounted for 3\%, children on a small area and the number of less expressed dissatisfaction with the "bag when it's too crowded, it is easy to fall, but also easy to mix up", "little friends is not enough, you see a (safety emergency bag)". The layout for 3\%, children are dissatisfied with the inconvenience, such as in the bathroom and a storage bucket in the classroom. It accounted for only 1\%, such as the locker or the push-pull bed is overweight.

\section{Research Conclusion}

The difficulty and function are the important factors of the quality of kindergarten facilities based on the children's perspectives. The less important factors include arrangement, physical character, allocation quantity, service and clean, opportunities and allowable time. 
Children's attitudes towards the facilities are obviously different from the adult. Respecting for children's opinions and suggestion can fully stimulate the enthusiasm of children to participate in the initiative and help to enhance their satisfaction with the environment. Thus, it will indirectly promote the facilities to create a more effective goal. Simultaneously, we should see that children are more concerned about the interesting things, difficulty and appearance color. However, they lack of the judgment abilities that the facilities can promote physical and mental health and the fact that the facilities may exert a subtle influence on all aspects of their abilities. Therefore, high estimation of children's mental ability without the education target will lead to the loss of the direction of education; but if we ignore the children's specific experience and the children's characteristics, it's hard to realize the good ideas and goals.

\section{References}

[1]National Association for the Education of Young Children, Guide to Accreditation, Washington D.C.: National Association for the Eduation of Young Children,1998:25

[2] Welsh Assembly Government (2004), The Foundation Phase in Wales: a draft framework for children's learning (Cardiff, National Assembly for Wales).

[3]Dion Sommer, Ingrid Pramling Samuelsson, KarstenHundeide, Child Perspectives and Children's Perspectives in Theory and Practice[M], New York:Springer, 2010:12.

[4] Hogan D. Researching 'the child' in developmental psychology [M]. London: Sage Publications, 2005:22-41

[5]Pimlott-Wilson H. Visualising children's participation in research: Lego Duplo,rainbows and clouds and moodboards[J]. International Journal of Social Research Methodology, 2012, 15(2): 135-148.

[6] Katz L G. Multiple perspectives on the quality of early childhood programmes[J]. European Early Childhood Education Research Journal, 1993, 1(2): 5-9.

[7]Rachel Blades, Vijay Kumari , Putting listening practice at the heart of early years practice-An evaluation of the Young Children's Voices Network[M], London: NCB Research Centre, 2011: 21-23

[8]Little, H., S. Wyver, F. Gibson, The influence of play context and adult attitudes on young children's physical risk-taking during outdoor play[J], European Early Childhood Education Research Journal,2011(19,1):113-131.

[9]Kennair L E O. Children's risky play from an evolutionary perspective: The anti-phobic effects of thrilling experiences[J]. Evolutionary Psychology, 2011, 9(2): 257-284.

[10]Little, H.,and S.Wyver.2008.Outdoor play:Does avoiding the risks reduce the benefits?[J],Australian Journal of Early Childhood 33, no. 2: 33-40.

[11]Wohlwill J F, Heft $\mathrm{H}$. The physical environment and the development of the child[J]. Handbook of environmental psychology, 1987, 1: 281-328. 